\title{
Impact of Nischarin on EMT regulators in breast cancer cell lines
}

\author{
YUAN-JIE CAI ${ }^{1}$, BO MA $^{1}$, MEI-LI WANG ${ }^{2}$, JIE CHEN $^{1}$, FU-GUANG ZHAO $^{1}$, JUAN-DI ZHOU $^{1}$, XU GUO $^{1}$, \\ LEI ZHENG ${ }^{1}$, CHUN-JING XU ${ }^{1}$, YI WANG ${ }^{2}$, YI-BO HE ${ }^{2}$, JIAN LIU ${ }^{3}$ and SHANG-NAO XIE ${ }^{2,3}$ \\ ${ }^{1}$ Department of Breast Surgery, Zhejiang Hospital, Hangzhou, Zhejiang 310030; ${ }^{2}$ Department of Breast Surgery, \\ Hangzhou Cancer Hospital, Hangzhou, Zhejiang 310000; ${ }^{3}$ Department of Breast Surgery, Zhejiang University Affiliated \\ Hangzhou First People Hospital, Hangzhou, Zhejiang 310000, P.R. China
}

Received March 17, 2020; Accepted July 24, 2020

DOI: $10.3892 / \mathrm{ol} .2020 .12154$

\begin{abstract}
Nischarin is an integrin-binding protein, which is well known as a novel tumor suppressor. In breast cancer, Nischarin serves a critical role in breast cancer cell migration and invasion. However, the molecular mechanism underlying the role of Nischarin remains unclear. Recent findings have demonstrated that epithelial-mesenchymal transition (EMT) increases the capacity of cell migration and invasion. As a member of the integrin family, it was hypothesized that Nischarin may regulate cellular processes via various signaling pathways associated with the EMT process. The present study detected the mRNA levels of EMT regulators via reverse transcription-quantitative PCR and related protein levels via western blotting in breast cancer cells, following $\mathrm{NISCH}$-overexpression and -knockdown. The results demonstrated that Nischarin inhibits cell proliferation, migration and invasion in breast cancer cells. Furthermore, when the NISCH gene was overexpressed, the relative mRNA level of E-cadherin was increased, while the relative mRNA levels of several transcription factors, such as Snail, ZEB1, N-cadherin, Slug, Twist1 and vimentin, decreased. When NISCH was silenced, these results were reversed. The present results demonstrated that Nischarin suppresses cell migration and invasion via inhibiting the EMT process.
\end{abstract}

\section{Introduction}

Within the past two decades, the novel protein Nischarin has been revealed to serve as a tumor suppressor in ovarian

Correspondence to: Mr. Shang-Nao Xie, Department of Breast Surgery, Hangzhou Cancer Hospital, 34 Yanguan Lane, Hangzhou, Zhejiang 310000, P.R. China

E-mail: xieshangnao@126.com

Dr Jian Liu, Department of Breast Surgery, Zhejiang University Affiliated Hangzhou First People Hospital, 261 Huansha Road, Hangzhou, Zhejiang 310000, P.R. China

E-mail: 13858068579liuj1224@sina.com

Key words: breast cancer, Nischarin, epithelial-mesenchymal transition, metastasis, migration, invasion, transcription factors and breast cancers (1-4). Nischarin expression levels are different in breast cancer cell lines with different degrees of malignancy (4). A decrease in the mRNA level of Nischarin is associated with an increase in cell invasiveness $(2,4)$. In human breast tissues, the expression level of Nischarin in cancerous tissues is significantly lower compared with that in non-cancerous tissues (2-4), lower in cancer tissues with lymph node metastasis compared with those without (3), lower in increasing grades 1-3 of invasive cancer tissues (2), and lower in advanced stage breast cancer tissues compared with those in the early stage (4).

Nischarin is an integrin-binding protein that binds the cytosolic domain of the integrin $\alpha 5$ subunit (5), and it is present in numerous animals (6). In humans, its expression has been identified in several tissues $(5,7)$. The roles of Nischarin in humans include serving as a neuroprotective protein that regulates neuronal migration (7), a regulator of brain function $(8,9)$, a regulator of blood pressure (10) and a tumor suppressor of ovarian and breast cancer $(1,2)$.

The molecular mechanism underlying the role of Nischarin is yet to be elucidated; however, it has been reported to inhibit cell migration and affect the cytoskeleton (5). Certain studies have reported the mechanisms underlying the effects of Nischarin on cell migration and invasion. Nischarin induces neuronal apoptosis via the PI3K and protein kinase B pathways (11), induces cell apoptosis in human breast cancer, and its expression is significantly correlated with estrogen receptor status (4). In addition, Nischarin inhibits Rac-induced migration and invasion in breast cancer cells via inhibiting p21-activated kinase (PAK1), LIM kinase 1 (LIMK1) (12-14) and the PAK-independent pathway (15). Nischarin interacts with liver kinase B1 (LKB1) to negatively regulate cell migration via the PAK-LIMK-Cofilin and cyclin D1/CDK4 pathways (16). Furthermore, Nischarin enhances cell proliferation and invasion by inhibiting the FAK-dependent signal transduction in human ovarian cancer (1). Nischarin prevents cell migration and invasion by altering the expression of key focal adhesion proteins (17). Additionally, Nischarin regulates cell motility via exosomes; when co-cultured with exosomes from Nischarin-positive cells, the survival ability, migration ability and adhesion of breast cancer cells are decreased (18). In Prkdc ${ }^{\text {scid }}$ mice xenograft tumor models, exosomes secreted by Nischarin-positive tumor cells inhibit tumor growth (18). 
As a member of the integrin family, integrin $\alpha 5 \beta 1$ is associated with the epithelial-mesenchymal transition (EMT) (19-22). Thus, it was hypothesized that Nischarin, a binding protein of integrin $\alpha 5 \beta 1(5,23)$, may serve a role in cell migration and invasion via regulating the EMT process. The present study used breast cancer cell lines with NISCH gene overexpression or knockdown to detect the mRNA and protein expression levels of EMT transcription regulators via reverse transcription-quantitative PCR (RT-qPCR) and western blotting. The current study revealed that Nischarin influences the EMT process via altering EMT-inducing transcription regulators.

\section{Materials and methods}

Cell culture. Hormone receptor positive (MCF-7), HER2 positive (SKBR3) and two triple negative breast cancer (MDA-MB-231 and Hs578T) cell lines, were purchased from the Cell Bank of the Chinese Academy of Sciences. The cells were cultured in Dulbecco's Modified Eagle's Medium (DMEM; Gibco; Thermo Fisher Scientific, Inc.) with 10\% fetal bovine serum (FBS) and $100 \mathrm{U} / \mathrm{ml}$ penicillin/streptomycin (Gibco; Thermo Fisher Scientific, Inc.) at $37^{\circ} \mathrm{C}$ and $5 \% \mathrm{CO}_{2}$. As the primary goal of the present study was to study the effects of Nischarin on triple-negative breast cancer cells, only the two triple negative breast cancer (MDA-MB-231 and Hs578T) cell lines were used in the next experiment.

Nischarin overexpression in Hs578T cells. Complete gene synthesis of the NISCH CDS (NM_007184) sequence, XhoI and $E c o$ RI restriction enzyme digestion, and ligation to the pcDNA3.1 vector (Youbao Bio; Hunan Keai Medical Devices Co., Ltd.) was performed to construct pcDNA3.1-Nischarin plasmids. Sequencing confirmed that DNA did not mutate from the sequence. A total of $4 \mu \mathrm{g}$ plasmid was transfected into Hs578T cells in $100 \mu \mathrm{l}$ serum-free DMEM at the logarithmic growth stage, using Lipofectamine 3000 (Invitrogen; Thermo Fisher Scientific, Inc.) according to the manufacturer's protocol at room temperature. pcDNA3.1 empty vector plasmid was used as a control and western blotting was used to validate the expression efficiency after $24 \mathrm{~h}$ transfection.

Inhibition of endogenous Nischarin in MDA-MB-231 cells via small interfering RNA (siRNA). A total of 3 NSICH-siRNAs were purchased from Shanghai GenePharma Co., Ltd. and their sequences are presented in Table I. Negative control siRNA (NC-siRNA) had a universal sequence of: Forward, 5'-UUCUCCGAACGUGUCACGUTT-3' and reverse, 5'-ACGUGACACGUUCGGAGAA-3'. siRNA (100 nm) was added to MDA-MB-231 cells at the logarithmic growth stage for transfection in $100 \mu \mathrm{l}$ serum-free DMEM and culture with Lipofectamine 3000 (Invitrogen; Thermo Fisher Scientific, Inc.), according to the manufacturer's protocol at room temperature. Western blotting was used to validate the silence efficiency after $24 \mathrm{~h}$ transfection. According to the results, all three NSICH-siRNAs had the ability to reduce $\mathrm{NISCH}$ gene expression, however, siRNA-1 showed the highest efficiency (Fig. 1B). Therefore, NSICH-siRNA-1 (labeled as siR-NISCH) was selected for further NISCH gene silencing experiments.
MTT experiment. NISCH-overexpressing Hs578T cells (transfected with pcDNA3.1-NISCH plasmids) or controls (transfected with pcDNA3.1 empty vector plasmids), and NISCH-silenced MDA-MB-231 cells (transfected with NISCH-siRNA1) or controls (transfected with NC-siRNA.) were seeded into a 96 -well plate at a density of $1 \times 10^{3}-1 \times 10^{4}$ and cultured for $72 \mathrm{~h}$ at $37^{\circ} \mathrm{C}$ with $5 \% \mathrm{CO}_{2}$. The cells were cultured for different durations $(24,48$ and $72 \mathrm{~h})$ to allow for formazan formation. MTT (50 $\mu$; Sigma-Aldrich; Merck KGaA) was added to $1 \mathrm{mg} / \mathrm{ml}$ PBS solution in each well and incubated for $1-4 \mathrm{~h}$ at $37^{\circ} \mathrm{C}$, and the absorbance at $570 \mathrm{~nm}$ was detected using a plate reader (Molecular Devices) to evaluate cell proliferation (24).

Colony formation assay. Hs578T cells with NISCH overexpression and the controls, and MDA-MB-231 cells with $\mathrm{NISCH}$-knockdown and the controls were seeded into 6-well plates at a density of 3000-10,000 cells/well, followed by culture for $2-3$ weeks at $37^{\circ} \mathrm{C}$. Colonies were fixed with $100 \%$ methanol for $20 \mathrm{~min}$ and then stained with $0.1 \%$ crystal violet for $20 \mathrm{~min}$ (25), both at room temperature.

Transwell cell migration and invasion assays. Serum-free DMEM (300 $\mu \mathrm{l})$ was added to the upper chamber and $800 \mu \mathrm{l}$ medium was added to the lower chamber of a Transwell plate, followed by incubation at $37^{\circ} \mathrm{C}$ for $2 \mathrm{~h}$ or overnight. Hs $578 \mathrm{~T}$ and MDA-MB-231 cells were transfected with plasmids or siRNA respectively and were serum starved for $24 \mathrm{~h}$. Subsequently, the culture medium used for the activation was removed, and $800 \mu \mathrm{l}$ medium containing 10\% FBS was added to the lower chamber of the Transwell plate. Matrigel was coated on the upper chamber for the invasion assay in cell culture incubator at $37^{\circ} \mathrm{C}$ for $30 \mathrm{~min}$, and Matrigel was not used for the migration assay. A total of $300 \mu \mathrm{l}\left(1 \times 10^{5}\right)$ serum-starved cells were added to the upper chamber. Following incubation for $24 \mathrm{~h}$ at $37^{\circ} \mathrm{C}$, the cells in the upper chamber were removed, and the invaded cells that had passed through the membrane were fixed using $100 \%$ methanol for $30 \mathrm{~min}$ and stained with $0.1 \%$ crystal violet for $20 \mathrm{~min}$, both at room temperature. Images were captured under a light microscope (magnification, $\mathrm{x} 40$ ) and $\geq 3$ fields were randomly selected for counting (26).

Western blotting. Western blot analysis for the protein was performed according to a previously published protocol (27). The total protein was extracted from the indicated cells using lysis buffer (1X PBS, $900 \mu \mathrm{l} ; 2.1 \mathrm{mg} / \mathrm{ml}$ Aprotinin, $10 \mu \mathrm{l}$; $1 \mathrm{mg} / \mathrm{ml}$ Leupeptin, $0.5 \mu \mathrm{l} ; 4.9 \mathrm{mg} / \mathrm{ml} \mathrm{MgCl}_{2}, 1 \mu \mathrm{l} ; 100 \mathrm{mM}$ Sodium Ortho-Vabadate, $10 \mu \mathrm{l}$; $10 \%$ Triton $\mathrm{X}-100,100 \mu \mathrm{l}$; and $100 \mathrm{mM}$ PMSF, $10 \mu \mathrm{l}$ ). Protein concentration was determined using the Pierce ${ }^{\circledR}$ Bicinchoninic Acid Protein Assay Reagent A kit (Thermo Fisher Scientific, Inc.). The absorbance value at $570 \mathrm{~nm}$ was determined and the protein concentration of the sample was calculated according to the standard curve. Equal amounts of protein $(20 \mu \mathrm{g} /$ lane) were separated via $4 \%$ SDS-PAGE and transferred to a polyvinylidene difluoride (PVDF) membrane (EMD Millipore). The sealed PVDF membrane was blocked with $5 \%$ fat free milk in PBS at room temperature for $2 \mathrm{~h}$, then it washed using 1X PBST buffer solution three times while being agitated (10 min each) at room temperature, and then transferred to a primary diluted solution 
Table I. NISCH siRNA sequences.

\begin{tabular}{lcc}
\hline NISCH siRNA & Forward $\left(5^{\prime} \rightarrow 3^{\prime}\right)$ & Reverse $\left(5^{\prime} \rightarrow 3^{\prime}\right)$ \\
\hline siRNA-1 & GCAGAGAGAAAGAUUGAUATT & UAUCAAUCUUUCUCUCUGCAA \\
siRNA-2 & CCGUUCGACCUAUCAAUAUTT & AUAUUGAUAGGUCGAACGGCA \\
siRNA-3 & GGAAGUCCUUGUUCCUGAATT & UUCAGGAACAAGGACUUCCTT
\end{tabular}

siRNA, small interfering RNA; NISCH, nischarin.

A

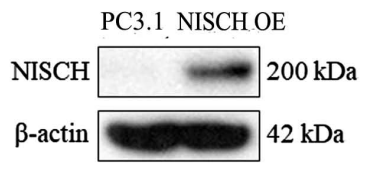

Hs578T

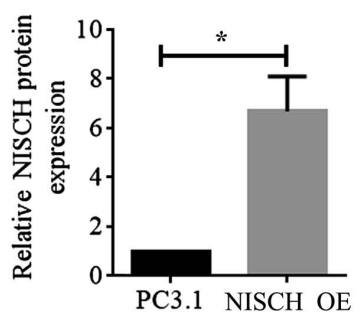

B
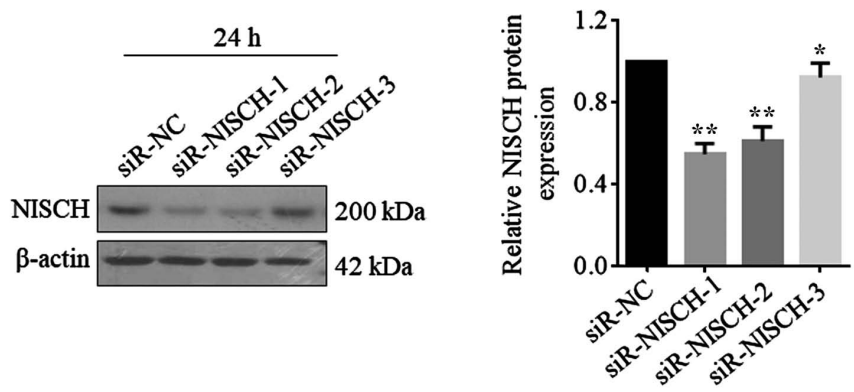

Figure 1. Hs578T cells overexpressed with Nischarin and NISCH silenced BDA-MB-231 cells. (A) Western blot analysis was performed for Hs578T cells transfected with pcDNA3.1-NISCH OE and PC3.1 plasmids were used as control. The relative Nischarin level was higher in cells transfected with pcDNA3.1-NISCH compared with the control cells, and a statistically significant difference was revealed at $24 \mathrm{~h}$. A two-tailed unpaired Student's t-test was used for comparisons in group. ${ }^{*} \mathrm{P}<0.05$. (B) MDA-MB-231 cells were transfected with three different siRNAs for $\mathrm{NISCH}$ silencing (siR-NISCH-1,-2,-3). Compared with siR-NC cells, the relative Nischarin protein expression level was significantly lower in siR-NISCH-1 at $24 \mathrm{~h}$. The statistical analysis used was one-way ANOVA. ${ }^{*} \mathrm{P}<0.05$ and ${ }^{* *} \mathrm{P}<0.01$ vs. siR-NC. NISCH, Nischarin; siR, small interfering RNA; PC3.1, pcDNA3.1 empty vector; NC, negative control; OE, overexpression.

with primary antibodies (dilution, $1: 1,000$ ) and incubated at $4^{\circ} \mathrm{C}$ overnight. The membrane was washed again using $1 \mathrm{X}$ PBST buffer solution three times while being agitated (10 min each) at room temperature. Followed by transfer to 1X PBST with secondary antibodies and incubation in a shaker at room temperature for $2 \mathrm{~h}$. The PVDF membrane was immersed in 1X PBST buffer and washed on a shaker three times (15 min each), and the specific protein bands were observed by utilizing a Precision Plus Protein ${ }^{\mathrm{TM}}$ Dual Color Standards (Bio-Rad Laboratories, Inc.). Primary antibodies against the following were used: NISCH (cat. no. D6T4X), ZEB1 (cat. no. E2G6Y), Slug Twist1 (cat. no. E7E2G), E-cadherin (cat. no. 4A2), Snail (cat. no. C15D3), N-cadherin (cat. no. D4R1H) and vimentin (cat. no. D21H3) (all from Cell Signaling Technology, Inc.). Goat anti-rabbit IgG secondary antibody conjugated with horseradish peroxidase (cat. no. BL003A; Biosharp Life
Sciences; dilution, 1:5,000) was also used. Protein bands were detected with an ECL chemiluminescence reaction kit (Thermo Scientific) and densitometry analysis was performed using ImageJ (version 1.38, National Institutes of Health).

RT-qPCR analysis. RT-qPCR analysis was performed as described previously (28). In brief, Hs578T cells with NISCH overexpression, MDA-MB-231 cells with NISCH-knockdown and their respective controls were lysed using TRIzol ${ }^{\circledR}$ reagent (Sigma-Aldrich; Merck KGaA) and total RNA was extracted. Total RNA was precipitated using isopropanol and then dissolved with DEPC- $\mathrm{H}_{2} \mathrm{O}$ (Generay Biotech). The first strand of cDNA was synthesized by M-MLV-inverse transferase using a RT-PCR kit (Promega Corporation) according to the manufacturer's protocol. An ABI 7300 real-time PCR system was used for qPCR amplification according to the manufacturer's protocols, with the $2 \mathrm{X}$ Power SYBR-Green PCR Master mix (Applied Biosystems). The thermocycling conditions were: Initial denaturation of $95^{\circ} \mathrm{C}$ for $10 \mathrm{~min}$, followed by 40 cycles of $95^{\circ} \mathrm{C}$ for $15 \mathrm{sec}$ for denaturation, $60^{\circ} \mathrm{C}$ for $1 \mathrm{~min}$ for annealing and elongation, followed by $95^{\circ} \mathrm{C}$ for $15 \mathrm{sec}$ and $60^{\circ} \mathrm{C}$ for $15 \mathrm{sec}$. The specificity of the amplification was determined by the DNA dissociation curve. The relative mRNA expression was determined by relative standard curve method $\left(2^{-\Delta \Delta \mathrm{Cq}}\right)$ (29) using $\beta$-actin as reference. The sequences of the primers are listed in Table II.

Statistical analysis. SPSS version 18 (SPSS, Inc.) was used for statistical analysis. A two-tailed unpaired Student's t-test was used for comparisons in group. One-way ANOVA followed by Tukey's post hoc test was used for comparisons between groups. $\mathrm{P}<0.05$ was considered to indicate a statistically significant difference.

\section{Results}

Expression of Nischarin protein in different breast cancer cell lines. Western blotting was performed to detect Nischarin basal expression in different breast cancer cell lines, including hormone receptor positive cell line (MCF-7), HER2 positive cell line (SKBR3) and two triple-negative cell lines (MDA-MB-231 and Hs578T). The expression levels of Nischarin were different in each cell line (Fig. S1) and the experiments were repeated three times. The present study, aimed at investigating the effect of changes in Nischarin protein levels on cell proliferation, colony formation, migration, invasion and EMT-related regulators in triple-negative breast cancer cell lines. Therefore, the two triple-negative cell lines (MDA-MB-231 and Hs578T) 
Table II. Primer sequences.

\begin{tabular}{lll}
\hline Primer & \multicolumn{1}{c}{ Forward $\left(5^{\prime} \rightarrow 3^{\prime}\right)$} & \multicolumn{1}{c}{ Reverse $\left(5^{\prime} \rightarrow 3^{\prime}\right)$} \\
\hline$\beta$-actin & AGCAGTTGTAGCTACCCGCCCA & GGCGGGCACGTTGAAGGTCT \\
NISCH & AGGGTGAACAGGGCGAGGAG & AGGCGGCGAACTGGCGGATA \\
ZEB1 & ACACGACCACAGATACGGCA & ATGGGAGACACCAAACCAAC \\
Twist 1 & CCTCCATCTGACACCTCC & CCCAGGCTCACATATTCC \\
Snail & CGACGACAGCCTGAGCAACA & CCACAGCCCGCAGACTTCTT \\
Vimentin & CCCAGCCCCAGCTACCACCT & GCCCCCTCTCCTCTTCCTTCTC \\
E-cadherin & TGCGTGAAATGGAAGAGAACTT & TGGGTATCAACCAGAGGGAGTG \\
N-cadherin & AGAGGCTTCTGGTGAAATCG & GGAAAGCTTCTCACGGCATA \\
\hline
\end{tabular}

NISCH, Nischarin.

were selected for further analysis. In addition, results for the expression levels of Nischarin showed that its expression in MDA-MB-231 cells was higher than that of Hs578T cells. Subsequently, MDA-MB-231 cells were selected for $\mathrm{NISCH}$ gene silencing and Hs578T cells were selected for NISCH gene overexpression.

Nischarin inhibits the proliferation and colony formation of breast cancer cells. Hs578T cells were transfected with pcDNA3.1-NISCH plasmids for overexpression of NISCH and with pcDNA3.1 empty vector as a control. Western blot analysis demonstrated that the protein expression of Nischarin increased after 24 and 48 h. As $N I S C H$-siRNA1 showed the most significant inhibition of the protein expression of Nischarin, $N I S C H$-siRNA1 was selected for silencing $N I S C H$ in MDA-MB-231 cells and it was confirmed that Nischarin protein expression was decreased when $\mathrm{NISCH}$ was silenced (Fig. 1). These results suggest that successful NISCH overexpression and knockdown were performed. In the MTT and colony formation assays, it was identified that when NISCH was overexpressed in Hs578T cells, the cell proliferation did not significantly change at 24,48 and $72 \mathrm{~h}$ (Fig. 2A); however, the colony formation decreased after 2 weeks (Fig. 2B). By contrast, the proliferation and colony formation of MDA-MB-231 cells increased following $\mathrm{NISCH}$ silencing (Fig. 2).

Nischarin inhibits the migration and invasion capacities of breast cancer cells. To understand the effects of Nischarin on the migration and invasion of breast cancer cells, these were investigated in breast cancer cells with NISCH overexpression and knockdown. Hs578T cells transfected with pcDNA3.1-Nischarin plasmids were used for $\mathrm{NISCH}$ gene overexpression analysis and pcDNA3.1 empty vector was used as a control (pcDNA3.1-control). MDA-MB-231 cells transfected with $N I S C H$-siRNA-1 were used for $N I S C H$-silencing analysis and cells transfected with NC-siRNA were used as a control. Using a Transwell assay, it was identified that the migration and invasion capacities were reduced in Hs578T cells with NISCH overexpression (Fig. 3A). By contrast, migration and invasion were enhanced in $\mathrm{NISCH}$-silenced MDA-MB-231 cells (Fig. 3B).
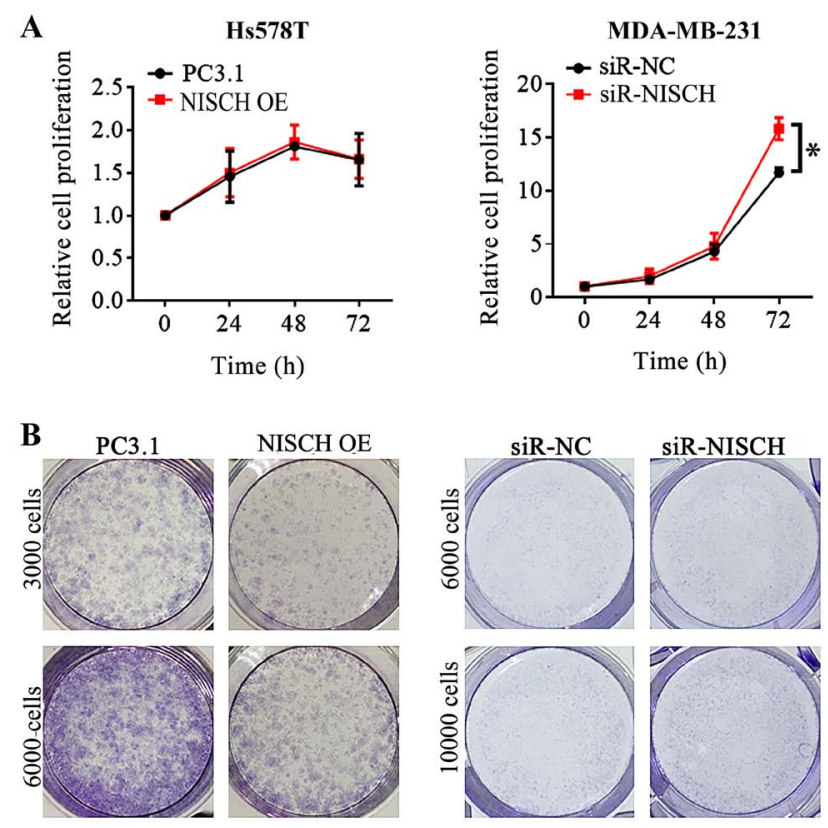

Figure 2. MTT experiment and colony formation assay for Hs578T cells with NISCH overexpressed and MDA-MB-231 cells with knocked down NISCH. (A) In MTT experiments, cells were seeded into a 96-well plate, each well contains $1 \times 10^{3}-1 \times 10^{4}$ cells. The relative cell proliferation was not significantly different between the Hs578T overexpressing NISCH and control cells, but it is increased in NISCH knockdown MDA-MB-231 cells than that in control cells at $72 \mathrm{~h}$. (B) In the colony formation assay, cells were seeded into 6-well plates at a density of 3000-10,000 cells/well, followed by culture for 2 weeks. The ability of colony formation decreased in NISCH overexpressed Hs578T cells and increased in NISCH knockdown MDA-MB-231 cells. ${ }^{\text {P }}<0.05$ vs. siR-NC. NISCH, Nischarin; siR, small interfering RNA; PC3.1, pcDNA3.1 empty vector; NC, negative control; OE, overexpression.

Influence of Nischarin on EMT regulators in breast cancer cells. The epithelial-related molecule E-cadherin, mesenchymal markers (N-cadherin and vimentin) and several EMT regulating transcription factors, including Twist, Snail, Slug and ZEB, are involved in the EMT process (30). RT-qPCR were performed to detect the mRNA expression levels of these factors in HS578T cells with NISCH overexpression and MDA-MB-231 cells with NISCH-knockdown. It was demonstrated that when NISCH was overexpressed, the mRNA expression level of E-cadherin increased, while the mRNA 
A
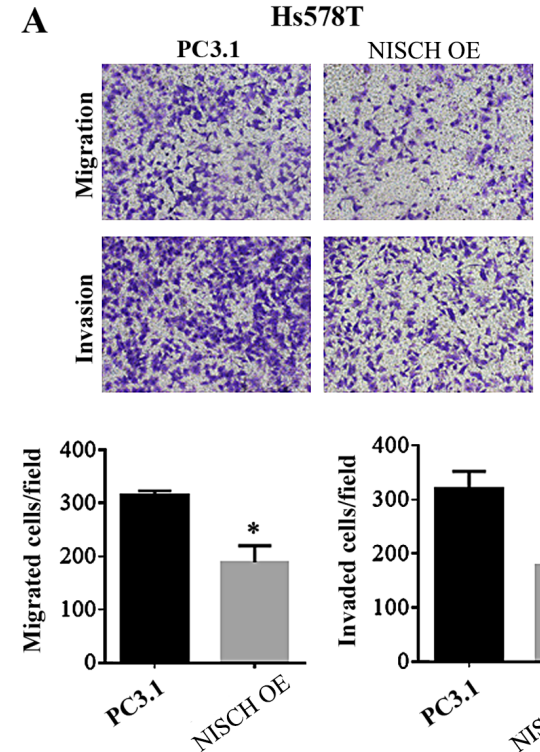

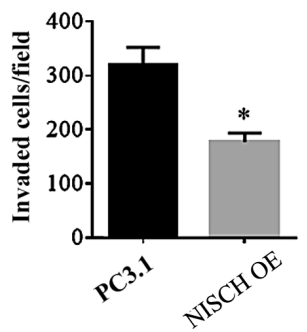

B
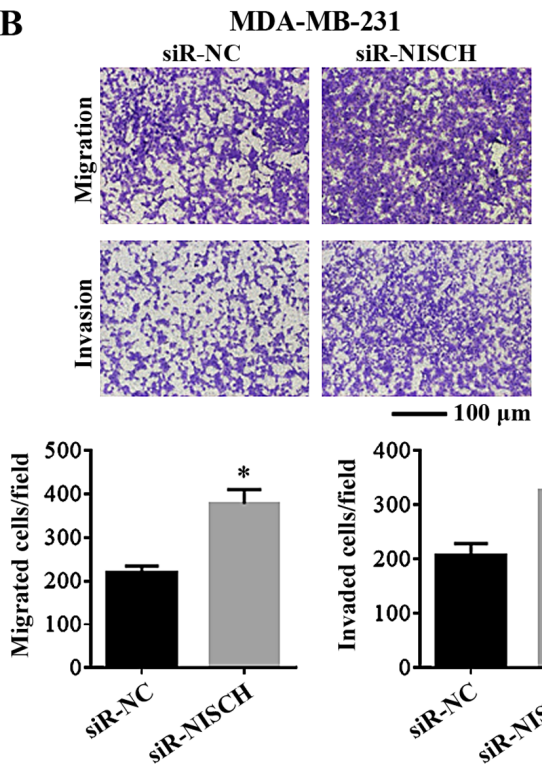

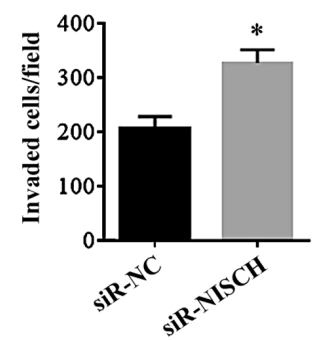

Figure 3. Transwell assay for cell migration and invasion. The ability of migration and invasion was inhibited in (A) NISCH overexpressed Hs578T cells $\left({ }^{*} \mathrm{P}<0.05\right.$ vs. PC3.1) and enhanced in (B) NISCH silenced MDA-MB-231 cells ( $\mathrm{P}<0.05$ vs. siR-NC). NISCH, Nischarin; siR, small interfering RNA; PC3.1, pcDNA3.1 empty vector; NC, negative control; OE, overexpression.

expression levels of Snail, ZEB1, N-cadherin, Slug, Twist1 and vimentin decreased (Fig. 4A). When $N I S C H$ was silenced, the mRNA expression level of E-cadherin was decreased, while that of Snail, N-cadherin, Slug, Twist1, ZEB1 and vimentin were increased (Fig. 4B). In a western blotting experiment for the proteins, Twist1, Slug and vimentin exhibited corresponding changes in expression levels (Fig. 5), but the remaining four proteins (E-cadherin, N-cadherin, ZEB, Snail) couldn't be successfully detected.

\section{Discussion}

It has been demonstrated in a number of studies that Nischarin suppresses tumor growth and metastasis of breast cancer $(2,4,6)$. Baranwal et al (2) examined Nischarin expression in 300 human breast cancer and normal tissue samples using RT-qPCR and immunohistochemistry. It was identified that the Nischarin mRNA expression level was higher in normal breast tissues compared with in cancerous tissues. In mice xenograft models, compared with parental MDA-MB-231 human breast cancer cells, tumor growth was significantly reduced in MDA-MB-231 cells that overexpressed Nischarin. In addition, lung metastases of these cells following tail vein injection were reduced for Nischarin-overexpressed MDA-MB-231 cells. In tumor xenografts, MCF-7 human breast cancer cells in which Nischarin expression was silenced grew significantly faster compared with the parental cells. Chang et al (4) demonstrated that overexpression of Nischarin may induce apoptosis and inhibit cell migration and invasion in breast cancer cell lines. Jain et al (16) reported that absence of both Nischarin and LKB1 enhances migration of MDA-MB-231 cells and tumor growth. The current study evaluated cell proliferation, migration and invasion of TNBC cell lines via MTT, colony formation and Transwell assays. It was identified that, following NISCH-overexpression, cell proliferation was not significantly altered; however, the colony formation, cell migration and invasion decreased in HS578T cells overexpressed with NISCH. Following NISCH knockdown in MBA-MD-231 cells, the cell proliferation, colony formation, migration and invasion were enhanced. Consistent with previous studies, the present results suggested that Nischarin serves an inhibitory role in the migration and invasion of breast cancer cells.

EMT is associated with the migration and invasion of cells, and it is a significant marker of cancer progression. Numerous studies have demonstrated the effect of EMT on breast cancer progression (30-33). EMT is a complex process characterized by loss of epithelial features and an increase in mesenchymal features. Studies have demonstrated E-cadherin is downregulated, vimentin and $\mathrm{N}$-cadherin are upregulated, and cytoskeletal recombination occurs in the EMT process (34-36). In addition, changes in the expression of integrins and other molecules associated with the extracellular matrix have also been observed (37). Numerous transcription factors are involved in the regulation of the EMT process, such as Snail, Slug, ZEB, Twist and $\beta$-catenin $(34,38,39)$. In the current study, when NISCH was overexpressed in Hs578T cells, the relative mRNA level of E-cadherin increased, while the mRNA levels of mesenchymal markers, including $\mathrm{N}$-cadherin and vimentin, decreased. In addition, the mRNA levels of EMT-promoting factors, such as Snail, ZEB, Twist1 and Slug decreased following NISCH overexpression. When NISCH was silenced in MDA-MB-231 cells, opposite results were observed. These results demonstrated that Nischarin inhibits the EMT process via inhibiting EMT transcription factors in breast cancer cells.

Major pathways involved in the EMT process in breast cancer have been found to involve the transforming growth factor- $\beta$ pathway, MAPK (FAS/RAF/MEK/ERK) pathway, E-cadherin loss, the Wnt/ $\beta$-Catenin pathway, Notch signaling, TNF- $\alpha$, hypoxia, certain miRNAs (30) and certain EMT-associated transcription factors (40). However, the specific EMT signaling pathway associated with Nischarin 
A $\mathbf{H s 5 7 8 T}$
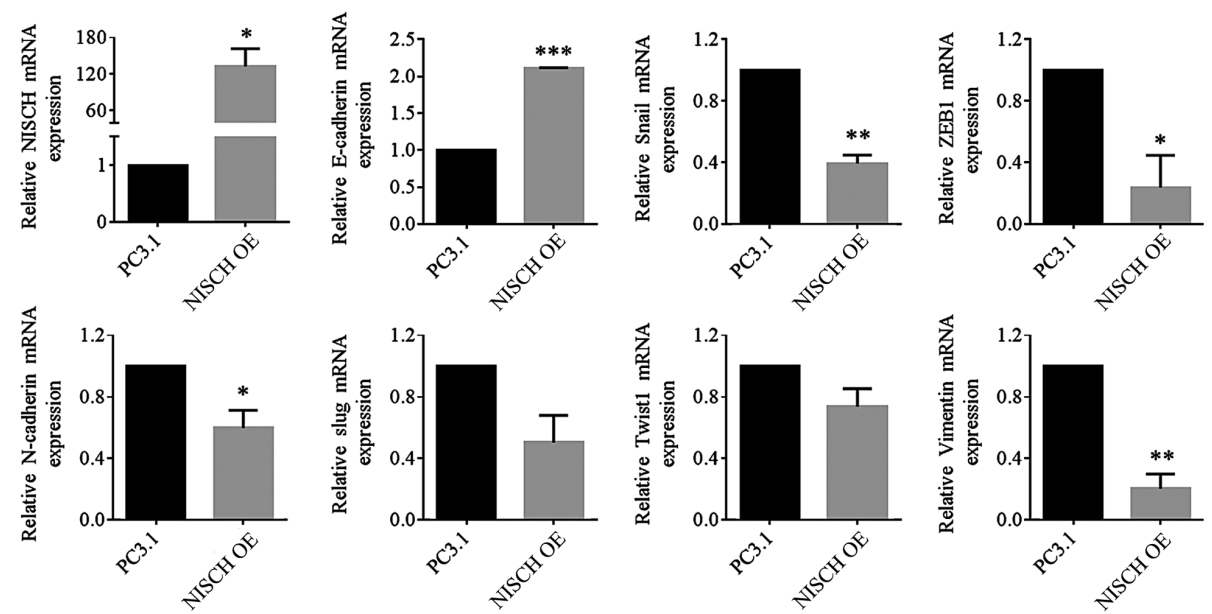

\section{B MDA-MB-231}
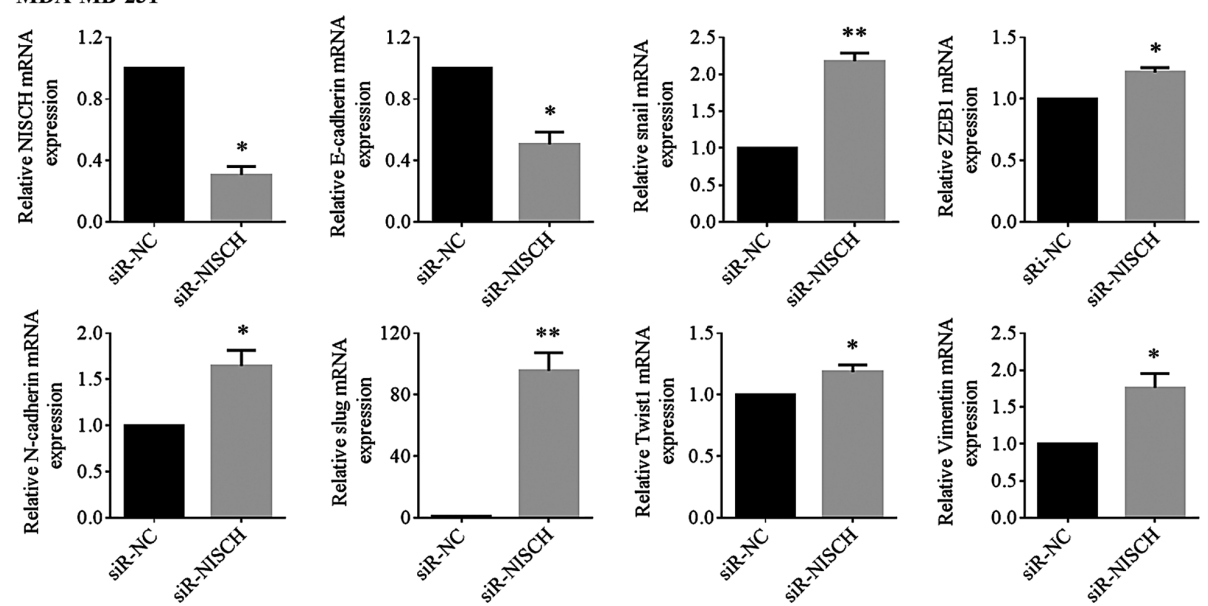

Figure 4. NISCH influences the expression of epithelial-mesenchymal transition-associated genes. The relative mRNAs level of E-cadherin, Snail, ZEB1, $\mathrm{N}$-cadherin, Slug, Twist1 and vimentin were detected in (A) HS578T cells overexpressed with NISCH $\left({ }^{*} \mathrm{P}<0.05 ;{ }^{* * *} \mathrm{P}<0.01\right.$ and ${ }^{* * * *} \mathrm{P}<0.001$ vs. $\left.\mathrm{PC} 3.1\right)$ and in (B) MDA-MB-231 cells with knocked down NISCH ( $\mathrm{P}<0.05$ and ${ }^{* *} \mathrm{P}<0.01$ vs. siR-NC). A two-tailed unpaired Student's t-test was used for statistical analysis in three independent samples. NISCH, Nischarin; siR, small interfering RNA; PC3.1, pcDNA3.1 empty vector; NC, negative control; OE, overexpression.
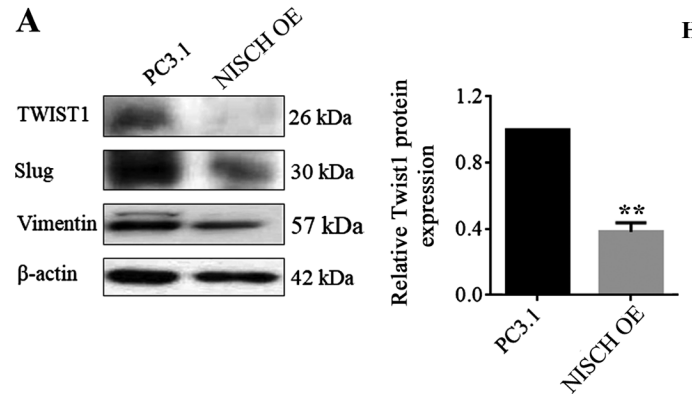

Hs578T
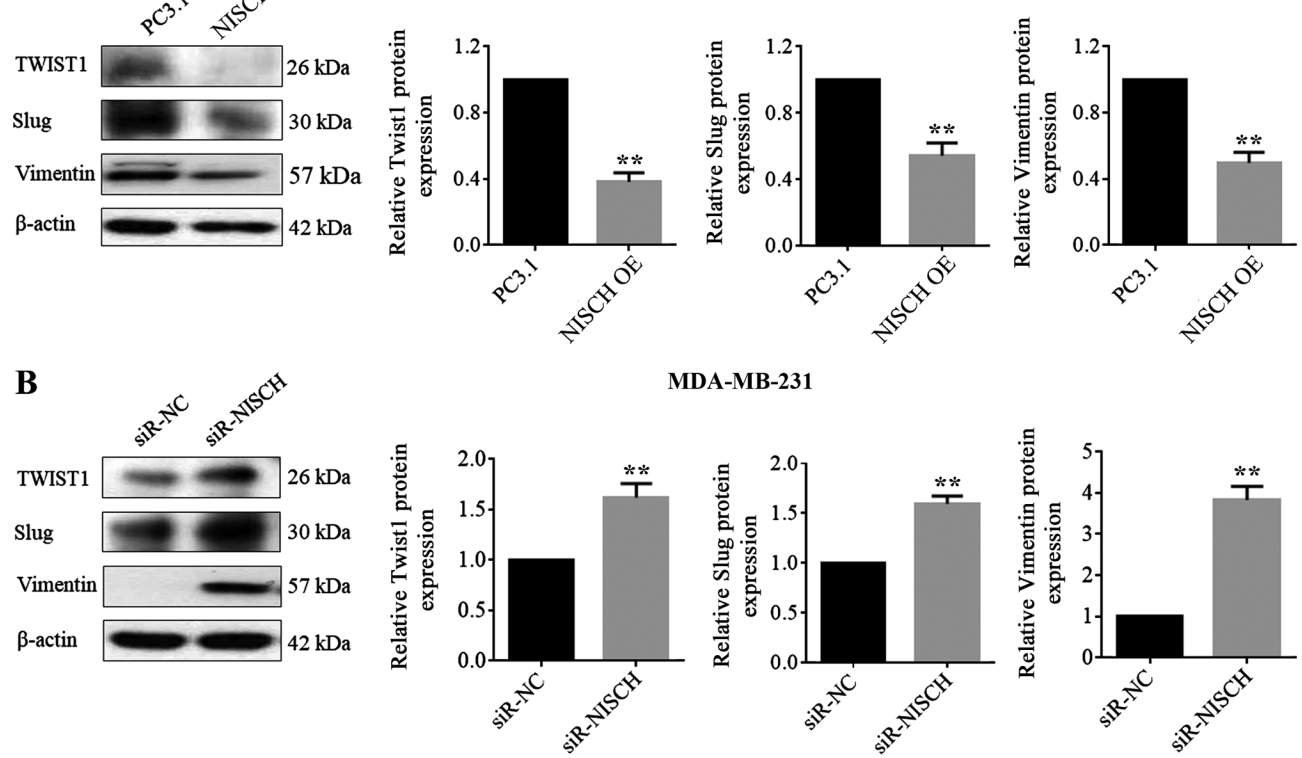

MDA-MB-231
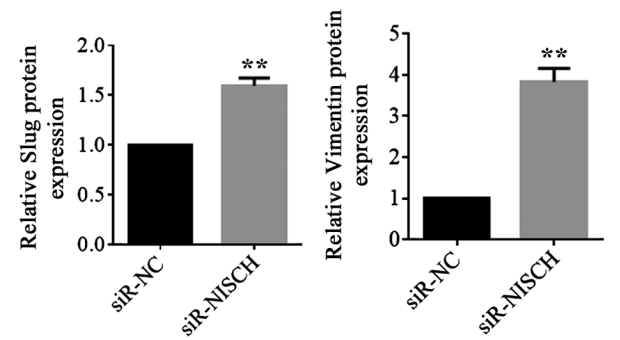

Figure 5. Protein expression levels of Twist1, Slug and vimentin in (A) NISCH over-expressed Hs578T cells (**P<0.01 vs. PC3.1) and (B) MDA-MB-231 cells with NISCH silenced $\left({ }^{* *} \mathrm{P}<0.01\right.$ vs. siR-NC). $\beta$-actin was used as the internal control. A two-tailed unpaired Student's t-test was used for statistical analysis. NISCH, Nischarin; siR, small interfering RNA; PC3.1, pcDNA3.1 empty vector; NC, negative control; OE, overexpression. 
remains unclear. A number of studies have demonstrated that Nischarin-associated signaling pathway proteins mainly include Rac1, PAK1, LIMK1 and LKB1 (12-16); however, the complete signaling cascade is yet to be elucidated. Baranwal et al (2) demonstrated that Nischarin regulates the expression of the $\alpha 5$ integrin, thereby influencing Rac-mediated signaling pathways to regulate tumor development. This previous study also identified that Nischarin regulates ERK phosphorylation via inhibiting PAK1. Nischarin can reduce ERK phosphorylation, which stimulates FAK and further ERK phosphorylation (2). The ERK family is a subfamily of proteins that is part of the MAPK family (41). It is widely known that the MAPK pathway is an important pathway in the EMT process (41). Therefore, Nischarin may impact the EMT process via the MAPK pathway; however, this was not determined in the present study as factors involved in this pathway, such as ERK, were not examined.

In conclusion, the current study revealed that Nischarin inhibits cell migration and invasion by inhibiting the EMT process via regulating the expression of EMT-associated transcription factors. The associations between Nischarin and EMT-associated transcription factors were demonstrated at the mRNA level. However, there were a number of limitations of this study. Firstly, corresponding changes at the protein level were not observed for all markers. Secondarily, numerous signaling pathways associated EMT can result in changes of these transcription factors, but the specific pathways underlying these changes could not be determined. Thirdly, mycoplasma was not tested in the current experiment. Although it was observed that the cells were a good length and normal shape, this may still have a potential influence on the experimental results. Mycoplasma pollution will lead to slower cell growth and worse state. Therefore, further experimental studies such as animal experiments are required to elucidate the underlying mechanism for how Nischarin impacts the breast cancer cells.

\section{Acknowledgements}

Not applicable.

\section{Funding}

This work was supported in part by the Medical Research Foundation of Zhejiang Province (grant no. LY18H040010) and the Zhejiang Medical and Health Science Project Fund (grant no. 2018KY189).

\section{Availability of data and materials}

All data generated or analyzed during this study are included in this published article.

\section{Authors' contributions}

SNX, YJC and BM conceived and designed the experiments. YJC, BM, SNX, MLW, YW and YBH performed the experiments. YJC, BM, SNX, JL, MLW, JC, FGZ, JDZ, XG, LZ and CJX analyzed the data. YJC, SNX, MLW, JC, FGZ, JDZ, XG, LZ, CJX, YW and YBH wrote the manuscript. All authors read and approved the final manuscript.

\section{Ethics approval and consent to participate}

Not applicable.

\section{Patient consent for publication}

Not applicable.

\section{Competing interests}

The authors declare that they have no competing interests.

\section{References}

1. Li J, He X, Dong R, Wang Y, Yu J and Qiu H: Frequent loss of NISCH promotes tumor proliferation and invasion in ovarian cancer via inhibiting the FAK signal pathway. Mol Cancer Ther 14: 1202-1212, 2015.

2. Baranwal S, Wang Y, Rathinam R, Lee J, Jin L, McGoey R, Pylayeva Y, Giancotti F, Blobe GC and Alahari SK: Molecular characterization of the tumor-suppressive function of nischarin in breast cancer. J Natl Cancer Inst 103: 1513-1528, 2011.

3. Chen J, Feng WL, Mo WJ, Ding XW and Xie SN: Expression of integrin-binding protein nischarin in metastatic breast cancer. Mol Med Rep 12: 77-82, 2015.

4. Chang C, Wei W, Han D, Meng J, Zhu F, Xiao Y, Wu G1, Shi X and Zhang L: Expression of nischarin negatively correlates with estrogen receptor and alters apoptosis, migration and invasion in human breast cancer. Biochem Biophys Res Commun 484: 536-542, 2017.

5. Alahari SK, Lee JW and Juliano RL: Nischarin, a novel protein that interacts with the integrin $\alpha 5$ subunit and inhibits cell migration. J Cell Bio 151: 1141-1154, 2000.

6. Maziveyi M and Alahari SK: Breast cancer tumor suppressors: A special emphasis on novel protein nischarin. Cancer Res 75 : 4252-4259, 2015.

7. Ding Y,Zhang R, Zhang K, Lv X, Chen Y, Li A, Wang L, Zhang X and Xia Q: Nischarin is differentially expressed in rat brain and regulates neuronal migration. PLoS One 8: e54563, 2013.

8. Kõ̃ks S, Luuk H, Nelovkov A, Areda T and Vasar E: A screen for genes induced in the amygdaloid area during cat odor exposure. Genes Brain Behav 3: 80-89, 2004.

9. Keller B, Mestre-Pinto JI, Álvaro-Bartolomé M, MartinezSanvisens D, Farre M, García-Fuster MJ, García-Sevilla JA, Torrens M; NEURODEP Group: A biomarker to differentiate between primary and cocaine-induced major depression in cocaine use disorder: The role of platelet IRAS/nischarin (I1-Imidazoline Receptor). Front Psychiatry 8: 258, 2017.

10. Zhang $\mathrm{J}$ and Abdel-Rahman AA: Inhibition of nischarin expression attenuates rilmenidine-evoked hypotension and phosphorylated extracellular signal-regulated kinase $1 / 2$ production in the rostral ventrolateral medulla of rats. J Pharmacol Exp Ther 324: 72-78, 2008.

11. Wu X, Xu W, Cui G, Yan Y, Wu X, Li L, Tan X, Wu Q and Gu X: The expression pattern of Nischarin after lipopolysaccharides (LPS)-induced neuroinflammation in rats brain cortex. Inflamm Res 62: 929-940, 2013.

12. Alahari SK: Nischarin inhibits Rac induced migration and invasion of epithelial cells by affecting signaling cascades involving PAK. Exp Cell Res 288: 415-424, 2003.

13. Alahari SK, Reddig PJ and Juliano RL: The integrin-binding protein nischarin regulates cell migration by inhibiting PAK. EMBO J 23: 2777-2788, 2004.

14. Ding Y, Milosavljevic T and Alahari SK: Nischarin inhibits LIM kinase to regulate cofilin phosphorylation and cell invasion. Mol Cell Biol 28: 3742-3756, 2008.

15. Reddig PJ, Xu D and Juliano RL: Regulation of p21-activated kinase-independent Racl signal transduction by nischarin. J Biol Chem 280: 30994-31002, 2005.

16. Jain P, Baranwal S, Dong S, Struckhoff AP, Worthylake RA and Alahari SK: Integrin-Binding protein nischarin interacts with tumor suppressor liver kinase B1 (LKB1) to regulate cell migration of breast epithelial cells. J Biol Chem 288: 15495-15509, 2013.

17. Maziveyi M, Dong S, Baranwal S and Alahari SK: Nischarin regulates focal adhesion and Invadopodia formation in breast cancer cells. Mol Cancer 17: 21, 2018. 
18. Maziveyi M, Dong S, Baranwal S, Mehrnezhad A, Rathinam R, Huckaba TM, Mercante DE, Park K and Alahari SK: Exosomes from nischarin-expressing cells reduce breast cancer cell motility and tumor growth. Cancer Res 79: 2152-2166, 2019.

19. Altevogt P, Doberstein K and Fogel M: L1CAM in human cancer. Int J Cancer 138: 1565-1576, 2016.

20. Sökeland G and Schumacher U: The functional role of integrins during intra- and extravasation within the metastatic cascade. Mol Cancer 18: 12, 2019.

21. Montgomery AM, Becker JC, Siu CH, Lemmon VP, Cheresh DA, Pancook JD, Zhao X and Reisfeld RA: Human neural cell adhesion molecule L1 and rat homologue NILE are ligands for integrin alpha v beta 3. J Cell Biol 132: 475-485, 1996.

22. Ruppert M, Aigner S, Hubbe M, Yagita H and Altevogt P: The L1 adhesion molecule is a cellular ligand for VLA-5. J Cell Biol 131: 1881-1891, 1995.

23. Alahari SK and Nasrallah H: A membrane proximal region of the integrin alpha5 subunit is important for its interaction with nischarin. Biochem J 377: 449-457, 2004

24. Grela E, Kozłowska J and Grabowiecka A: Current methodology of MTT assay in bacteria-A review. Acta Histochem 120: 303-311, 2018.

25. Guzmán C, Bagga M, Kaur A, Westermarck J and Abankwa D: ColonyArea: An imageJ plugin to automatically quantify colony formation in clonogenic assays. PLoS One 9: e92444, 2014.

26. Justus CR, Leffler N, Ruiz-Echevarria M and Yang LV: In vitro cell migration and invasion assays. J Vis Exp 88: e51046, 2014.

27. Liu Q, Li X, Bao YS, Lu J, Li H, Huang Z and Liu F: Chemical synthesis and functional characterization of a new class of ceramide analogues as anti-cancer agents. Bioorg Med Chem 27: 1489-1496, 2019.

28. Sun JG, Ruan F, Zeng XL, Xiang J, Li X, Wu P, Fung KP and Liu FY: Clitocine potentiates TRAIL-mediated apoptosis in human colon cancer cells by promoting mcl-1 degradation. Apoptosis 21: 1144-1157, 2016.

29. Livak KJ and Schmittgen TD: Analysis of relative gene expression data using real-time quantitative PCR and the 2(-Delta Delta C(T)) method. Method 25: 402-408, 2001.

30. Lima JF, Nofech-Mozes S, Bayani J and Bartlett JM: EMT in breast carcinoma-a review. J Clin Med 5: 65, 2016

31. Bouris P, Skandalis SS, Piperigkou Z, Afratis N, Karamanou K, Aletras AJ, Moustakas A, Theocharis AD and Karamanos NK Estrogen receptor alpha mediates epithelial to mesenchymal transition, expression of specific matrix effectors and functional properties of breast cancer cells. Matrix Biol 43: 42-60, 2015.
32. Radisky ES and Radisky DC: Matrix metalloproteinase-induced epithelial-mesenchymal transition in breast cancer. J Mammary Gland Biol Neoplasia 15: 201-212, 2010.

33. Cichon MA, Nelson CM and Radisky DC: Regulation of epithelial-mesenchymal transition in breast cancer cells by cell contact and adhesion. Cancer Inform 14: 1-13, 2015.

34. Lamouille S, Xu J and Derynck R: Molecular mechanisms of epithelial-mesenchymal transition. Nat Rev Mol Cell Biol 15: 178-196, 2014.

35. Onder TT, Gupta PB, Mani SA, Yang J, Lander ES and Weinberg RA: Loss of E-cadherin promotes metastasis via multiple downstream transcriptional pathways. Cancer Res 68: 3645-3654, 2008.

36. Gregoire JM, Fleury L, Salazar-Cardozo C, Alby F, Masson V, Arimondo PB and Ausseil F: Identification of epigenetic factors regulating the mesenchyme to epithelium transition by RNA interference screening in breast cancer cells. BMC Cancer 16: 700,2016

37. Zañudo JM, Guinn MT, Farquhar K, Szenk M, Steinway SN, Balázsi G and Albert R: Towards control of cellular decision-making networks in the epithelial-to-mesenchymal transition. Phys Biol 16: 031002, 2019.

38. Wang Y, Shi J, Chai K, Ying X and Zhou BP: The role of snail in EMT and tumorigenesis. Curr Cancer Drug Targets 13: 963-972, 2013.

39. Mrozik KM, Blaschuk OW, Cheong CM, Zannettino AC and Vandyke K: N-Cadherin in cancer metastasis, its emerging role in haematological malignancies and potential as a therapeutic target in cancer. BMC Cancer 18: 939, 2018.

40. Olea-Flores M, Juárez-Cruz JC, Mendoza-Catalán MA, Padilla-Benavides T and Navarro-Tito N: Signaling pathways induced by leptin during epithelial-mesenchymal transition in breast cancer. Int J Mol Sci 19: 3493, 2018.

41. Olea-Flores M, Zuñiga-Eulogio MD, Mendoza-Catalán MA, Rodríguez-Ruiz HA, Castañeda-Saucedo E, Ortuño-Pineda C, Padilla-Benavides T and Navarro-Tito N: Extracellular-Signal regulated kinase: A central molecule driving epithelial-mesenchymal transition in cancer. Int J Mol Sci 20: 2885, 2019.

This work is licensed under a Creative Commons Attribution-NonCommercial-NoDerivatives 4.0 International (CC BY-NC-ND 4.0) License. 